\title{
Impact of single-walled carbon nanotubes on the embryo: a brief review
}

\author{
This article was published in the following Dove Press journal: \\ International Journal of Nanomedicine \\ 21 January 2016 \\ Number of times this article has been viewed
}

\author{
Ala-Eddin Al Moustafa ${ }^{1-4}$ \\ Etienne Mfoumou ${ }^{5}$ \\ Dacian E Roman ${ }^{3}$ \\ Vahe Nerguizian ${ }^{6}$ \\ Anas Alazzam ${ }^{7}$ \\ Ion Stiharu ${ }^{3}$ \\ Amber Yasmeen ${ }^{8}$ \\ 'College of Medicine \& Biomedical \\ Research Centre, Qatar University, \\ Doha, Qatar; ${ }^{2}$ Oncology Department, \\ McGill University, ${ }^{3}$ Mechanical and \\ Industrial Engineering Department, \\ Concordia University, Montreal, QC, \\ Canada; ${ }^{4}$ Syrian Research Cancer \\ Centre of the Syrian Society against \\ Cancer, Aleppo, Syria; ${ }^{5}$ Nova Scotia \\ Community College, Dartmouth, NS, \\ 'École de Technologie Supérieure, \\ Montreal, QC, Canada; ${ }^{7}$ Department \\ of Mechanical Engineering, Khalifa \\ University, Abu Dhabi, UAE; ${ }^{8}$ Segal \\ Cancer Centre, Lady Davis Institute \\ for Medical Research of the Sir \\ Mortimer B. Davis-Jewish General \\ Hospital, Montreal, QC, Canada
}

Correspondence: Ala-Eddin Al Moustafa College of Medicine \& Biomedical Research Centre, Qatar University, PO Box: 27I3, Doha, Qatar Email aalmoustafa@qu.edu.qa

\begin{abstract}
Carbon nanotubes (CNTs) are considered one of the most interesting materials in the 21 st century due to their unique physiochemical characteristics and applicability to various industrial products and medical applications. However, in the last few years, questions have been raised regarding the potential toxicity of CNTs to humans and the environment; it is believed that the physiochemical characteristics of these materials are key determinants of CNT interaction with living cells and hence determine their toxicity in humans and other organisms as well as their embryos. Thus, several recent studies, including ours, pointed out that CNTs have cytotoxic effects on human and animal cells, which occur via the alteration of key regulator genes of cell proliferation, apoptosis, survival, cell-cell adhesion, and angiogenesis. Meanwhile, few investigations revealed that CNTs could also be harmful to the normal development of the embryo. In this review, we will discuss the toxic role of single-walled CNTs in the embryo, which was recently explored by several groups including ours.
\end{abstract}

Keywords: single-walled carbon nanotubes, embryo, toxicity

\section{Introduction}

The 21 st century has seen an emergence of nanotechnology, which has been applied to a wide range of scientific disciplines including agri-food industry, electrical and electronic equipment, and construction. ${ }^{1-8}$ Another area of application is in the realm of nanoparticles (NPs) use in medicine, giving rise to the field of nanomedicine. This field holds the promise of providing great benefits for society in the future, ${ }^{9-11}$ but the toxicity of the NPs still needs more investigations.

Nanomaterials have sizes ranging from approximately 1 nanometer up to several hundred nanometers, comparable to many biological macromolecules such as enzymes, antibodies, DNA plasmids, and others. In this size range, materials exhibit interesting physical properties, distinct from both the molecular and bulk scales, present new opportunities for biomedical research and applications in various areas including biology and medicine. ${ }^{12,13}$ In the latter, carbon nanotubes (CNTs) offer a wide range of applications due to their unique atomic configuration, optical, mechanical and electronic properties, high surface-area-to-volume ratios, and easy functionalization. ${ }^{14,15}$ The use of these NPs in humans for diagnostic or treatment purposes would involve considerable exposure to particles and therefore understanding their effect is of paramount importance. ${ }^{16-19}$ Although several in vitro and in vivo studies have been undertaken in the past few years on their toxicity, ${ }^{16,17,20-24}$ a comprehensive knowledge of their effects is still far from being obtained. This gap is even larger when considering their effects on embryonic development, for which only sparse data are available. ${ }^{25-30}$ Most of these studies have focused on zebrafish embryo because it is easy to manipulate. However, other models were used to explore the effect of CNTs in the embryo such 

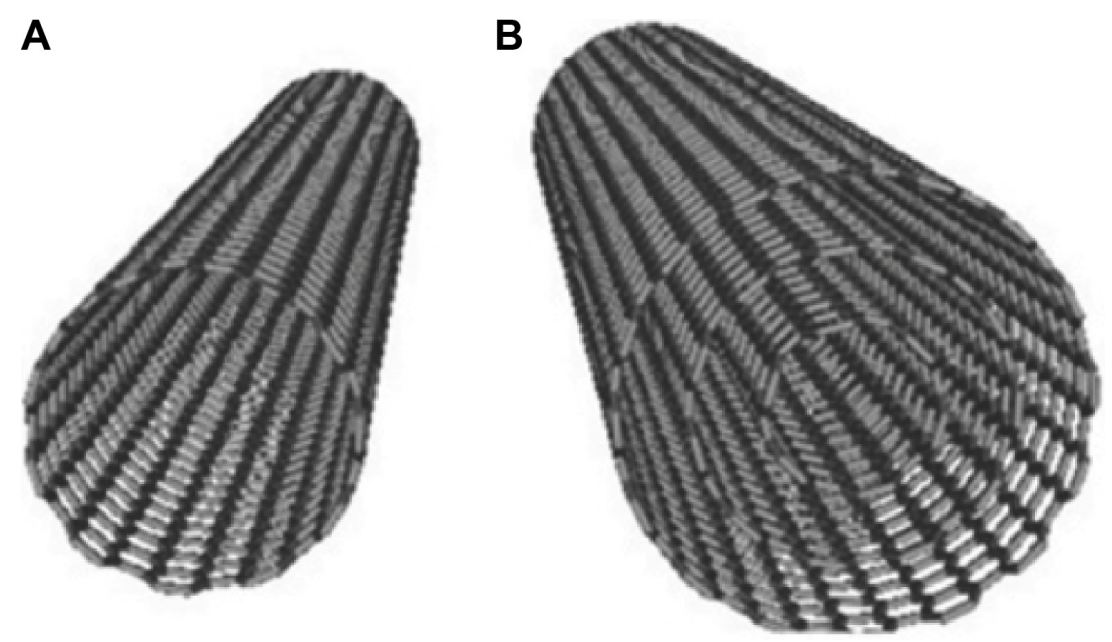

Figure I Different types of CNTs: (A) SWCNT and (B) MWCNT.

Abbreviations: CNTs, carbon nanotubes; MWCNT, multiwalled carbon nanotube; SWCNT, single-walled carbon nanotube.

as chicken and mouse. ${ }^{28,29}$ These studies revealed clearly that CNTs could harm the normal development of the embryo. CNTs are classified as single-walled carbon nanotubes (SWCNTs) and multiwalled carbon nanotubes (MWCNTs), which differ in the arrangement of their graphene cylinders. SWCNTs contain only one single layer of graphene, while MWCNTs have many layers, ${ }^{31,32}$ as illustrated in Figure 1. The present review focuses on the toxicity of SWCNTs in the normal development of the embryo.

\section{Single-walled carbon nanotubes}

SWCNTs are monocylindrical carbon layers, made of hollow graphitic nanomaterials with a diameter range of 0.4-2 nm, built from carbon atoms; their structures are organized in harmony with helical, armchair, zigzag, and chiral arrangements. ${ }^{33-35}$ These one-dimensional NPs with capability to behave distinctly from spherical NPs in biology offer new opportunities in biomedical research. The nanotubes are flexible and able to bend, facilitating multiple binding sites of a functionalized nanotube to one cell; this leads to a multivalence effect and improved affinity of nanotubes conjugated with targeting ligands. ${ }^{36,37}$

SWCNTs have raised considerable interest worldwide due to their unique shape and the resulting versatile and unique properties. ${ }^{34,38-40}$ Numerous studies have presented them in the form of seamless concentric tubes. ${ }^{38,41,42}$ SWCNTs are highly absorbing materials with a strong optical absorption in the near-infrared range because of the first optical transition (E11); therefore, SWCNTs have been utilized in photothermal applications, ${ }^{10,43-45}$ and photoacoustic imaging. ${ }^{46,47}$ Moreover, when semiconducting, SWCNTs with small band gaps (approximately $1 \mathrm{eV}$ ), exhibit photoluminescence in the near-infrared range. The emission range of SWCNTs was found to be $800-2,000 \mathrm{~nm},{ }^{48,49}$ which covers the biological tissue transparency window, and is therefore suitable for biological imaging.

In human health, it is important to rapidly and accurately detect glucose levels in biological environments, especially for diabetes mellitus; for this purpose, Chen et $\mathrm{al}^{20}$ have recently proposed an accurate, highly sensitive, convenient, low cost, and disposable glucose biosensor on a single chip, functionalized through a layer-by-layer assembly of SWCNTs and multilayer films of different needed types. Moreover, Giraldo et $\mathrm{al}^{50}$ have investigated the separation and functionalization of SWCNT by their electronic type; this has enabled the development of ratiometric fluorescent SWCNT sensors, used to detect trace analytes in complex environments such as strongly scattering media and biological tissues. ${ }^{50}$ However, their toxic effect on human health could have an important impact on their use worldwide; presently, it was demonstrated that SWCNTs have a toxic effect on cells, including human normal cells, and living organisms. ${ }^{24,51-53}$ The toxic effect of these NPs could be influenced by a number of factors including the surface chemistry, surface area, functional groups, shape, photochemistry, charge, and aggregation as well as preparation method. ${ }^{6,24,54}$ Hence, we will review the recent publications related to the effect of SWCNTs on embryo development, which is unfortunately limited to a few number of studies including one from our group.

\section{SWCNTs in the embryo}

Today, SWCNTs have widespread applications in many technological fields; however, several studies demonstrated that pulmonary deposition of SWCNTs causes acute 
Table I Summarize the outcome of SWCNTs on the embryo

\begin{tabular}{lll}
\hline Embryo & Outcome & References \\
\hline Drosophila & No toxicity & 62,63 \\
Zebrafish & Hatching delay & 26,30 \\
Avian & Cytotoxic effect on glial and neurons cells & 64 \\
& Inhibition of angiogenesis, gene deregulation, and abnormal development & 28 \\
Mouse & Increase of reactive oxygen species, malformation, and skeletal abnormalities & 63,65 \\
& Cytotoxic effects and DNA damages on embryonic cells & 66 \\
& Low cell proliferation and viability of glioblastoma cells & 67 \\
Hamster & Apoptotic effect and DNA damage on mouse embryonic cells & 29 \\
\hline
\end{tabular}

Abbreviation: SWCNT, single-walled carbon nanotube.

pulmonary inflammation, as well as chronic responses such as fibrosis. ${ }^{31,55-61}$ On the other hand, we have identified a list of genes that are differentially expressed between matched primary human normal bronchial epithelial (HNBE) cells exposed to SWCNTs and unexposed ones using microarray technology. Our data showed that SWCNTs inhibit and provoke cell proliferation and apoptosis, respectively, through the deregulation of several important gene controllers of cell survival and apoptosis. ${ }^{51}$ These studies suggest that SWCNTs can induce toxicity in bronchial tissues and probably other organ tissues of the exposed organisms. In parallel, it was demonstrated by few investigations, including ours, that SWCNTs can affect the embryo of the exposed organisms. Herein, we will review the outcome of SWCNTs on the embryo of several organisms from Drosophila to mammalian (Table 1).

\section{SWCNTs and Drosophila embryo}

Few groups investigated the effect of SWCNTs on Drosophila embryo; however, they did not observe any toxicity in this organism. ${ }^{62,63}$

\section{SWCNTs and aquatic embryo}

Cheng et $\mathrm{al}^{27}$ explored the impact of raw SWCNTs on the embryo of aquatic organisms using zebrafish embryos. They reported that SWCNTs induce a significant hatching delay in the zebrafish embryos between 52 and 72 hours postfertilization (hpf) at concentrations greater than $120 \mathrm{mg} / \mathrm{L}$. Meanwhile, they revealed that the embryonic development of the exposed embryos (up to $96 \mathrm{hpf}$ ) is not affected at SWCNT concentrations of up to $360 \mathrm{mg} / \mathrm{L}$. In parallel, they indicated that the chorion of zebrafish embryos is an effective protective barrier to SWCNT agglomerates. Finally, they stated that the hatching delay observed in their study is likely induced by the $\mathrm{Co}$ and $\mathrm{Ni}$ catalysts used in the production of SWCNTs, which remained at trace concentrations after purification. However, a recent study revealed that SWCNTs can provoke hatching delay in the zebrafish embryos; the main mechanism of hatching inhibition by SWCNTs and other NPs is likely related to the interaction of NPs with the zebrafish hatching enzyme. ${ }^{30}$

\section{SWCNTs and avian embryo}

Belyanskaya et a ${ }^{64}$ showed that SWCNT suspensions could induce acute toxic effects in primary cultures from both the central and peripheral nervous systems of chicken embryos. The level of toxicity is partially dependent on the agglomeration state of these particles. Therefore, the authors suggested that SWCNTs are likely to cause adverse effects on glial cells and neurons if the nervous system is exposed to high concentrations. ${ }^{64}$

On the other hand, our group has investigated the effect of SWCNTs on the chicken embryo at the third day of incubation. ${ }^{28} \mathrm{We}$ deposited $25 \mu \mathrm{g}$ of SWCNTs, diluted in $25 \mu \mathrm{L}$ of phosphate-buffered saline, on the embryos. We reported that SWCNTs treatment inhibits the angiogenesis of the chorioallantoic membrane and in the chicken embryo, especially in the brain and the liver (Figure 2). Meanwhile, our study revealed that SWCNTs can harm the normal development of the embryo since all SWCNTs-exposed embryos are smaller in comparison with the controls. We also noted that the majority SWCNTs-exposed embryos die before 12 days of incubation. Macroscopic examination did not reveal any anomalies in these embryos. However, histological analysis of liver tissues from these embryos revealed an important necrosis and inhibition of blood vessels development.

In order to define gene targets of SWCNTs in the embryo, we examined the expression patterns of INHBA, ATF-3, FOXA-2, CASPAS-8, MAPRE2, BCL-2, RIPK-1, Cadherin-6 type-2, SPI-4, KIF-14, and VEGF-C genes in brain and liver tissues from SWCNTs-treated and their matched control embryos; these selected genes were recently identified, by our group, as major gene targets of SWCNTs in HNBE cells. ${ }^{51}$ Our investigation revealed that INHBA, 

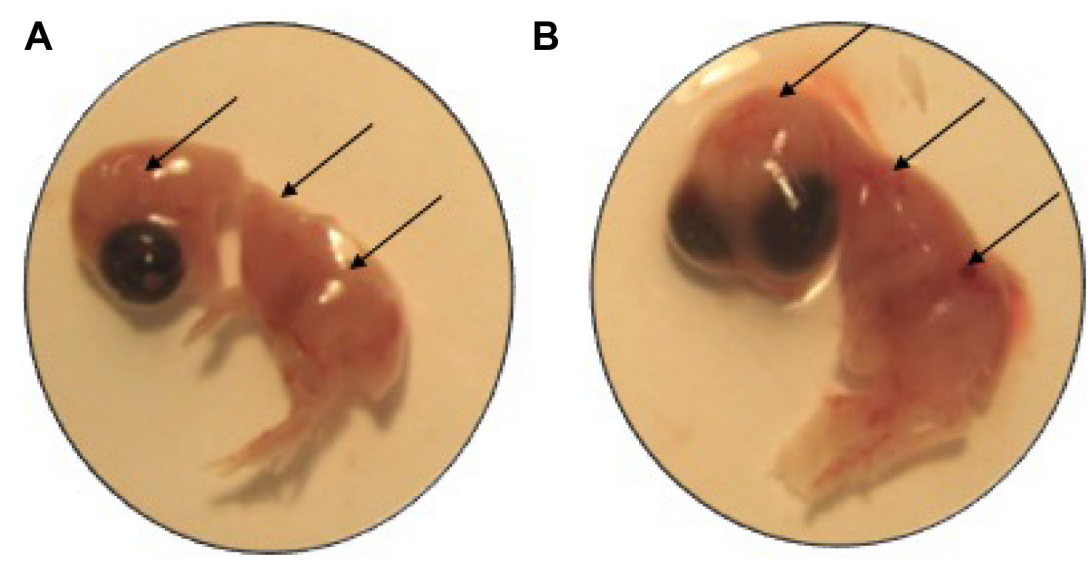

Figure 2 Outcome of SWCNTs on the chicken embryo at 12 days of incubation.

Notes: The SWCNTs-exposed embryo (A) is smaller in comparison with its matched control (B). Additionally, we note that SWCNTs inhibit blood vessels development in SWCNTs-treated embryo in comparison with the control (arrows). The embryos were treated by $25 \mu \mathrm{g}$ of SWCNTs at 3 days of incubation, reprinted from Nanomedicine, 2013;9(7), Roman D, Yasmeen A, Mireuta M, Stiharu I, Al Moustafa AE, Significant toxic role for single-walled carbon nanotubes during normal embryogenesis, Pages 945-950, ${ }^{28}$ Copyright (C2013, with permission from Elsevier.

Abbreviation: SWCNTs, single-walled carbon nanotubes.

ATF-3, FOXA-2, CASPAS-8, MAPRE2, BCL-2, RIPK-1 genes are upregulated, while Cadherin-6 type-2, SPI-4, KIF-14, and VEGF-C are downregulated in brain and liver tissues of SWCNTs-exposed embryos in comparison with their matched tissues from control embryos; these data are consistent with our microarray data in HNBE cells.

\section{SWCNTs and mammalian embryo}

Pietroiusti et a ${ }^{65}$ explored the effect of pristine and oxidized SWCNTs on the development of the mouse embryo. In this study, SWCNTs (from $10 \mathrm{ng}$ to $30 \mu \mathrm{g} /$ mouse) were administered to female mice after implantation (postcoital day 5.5). The authors revealed that there was a high percentage of early miscarriages and fetal malformations in females exposed to oxidized SWCNTs, and lower percentages in animals exposed to the pristine material. The lowest effective dose was identified as $100 \mathrm{ng} /$ mouse. Meanwhile, they reported extensive vascular lesions and increased production of reactive oxygen species in placentas of malformed embryo but not in normally developed fetuses. The data of this investigation clearly suggest that SWCNTs could act as embryotoxic agents in mammals. ${ }^{65}$ Meanwhile, Philbrook et al ${ }^{63}$ demonstrated that oral administration of SWCNTs $(10 \mathrm{mg} / \mathrm{kg})$ to pregnant CD-1 mice during organogenesis leads to increased resorptions, external morphological defects, and skeletal abnormalities.

Later on, Yang et $\mathrm{al}^{66}$ investigated the cytotoxicity, genotoxicity, and oxidative effects of SWCNTs on primary mouse embryo fibroblast (MEF) cells. They revealed that these particles have moderately cytotoxic effect but can induce more DNA damage in comparison with other NPs such as zinc dioxide. The authors also argued that the potential genotoxicity of these NPs could be attributed to the particle shape ${ }^{66}$ On the other hand, Bobrinetskii et al ${ }^{67}$ examined the effect of SWCNTs on cell viability and proliferation of human embryo fibroblasts and glioblastoma cells. They found that SWCNTs have a low cytotoxic activity on these cells.

Earlier, Tong et $\mathrm{al}^{29}$ explored the role of the p21 and hus1 genes in the toxicity of SWCNTs on wild type and $\mathrm{p} 21^{-/-}$, hus $1^{+/+}$MEF cells. They revealed that the yield of the micronucleus ratio in $\mathrm{p} 21$ gene knockout MEF cells is lower than that in their wild type counterpart, which can suggest that p21 might play a role as antiapoptosis factor during the signal transduction of DNA damage caused by SWCNTs in mammalian embryonic cells. ${ }^{29}$

Recently, Darne et al ${ }^{12}$ examined the outcome of SWCNTs on Syrian hamster embryo cells; they found that SWCNTs induce cytotoxic and genotoxic effects in this cell line.

Finally, we believe that it is important to review the biomedical utility of using SWCNTs with other molecules during gestation in mammals. Bari et al ${ }^{68}$ investigated the outcome of carboxylic acid functionalized single-walled carbon nanotubes (f-SWCNT-COOH) on nonenriched hematopoietic stem and progenitor cells in human umbilical cord blood-mononucleated cells. The authors of this investigation reported that $\mathrm{f}-\mathrm{SWCNT}-\mathrm{COOH}$ can increase the viability of the CD45(+) cells even without cytokine stimulation; it also reduced mitochondrial super oxides and 


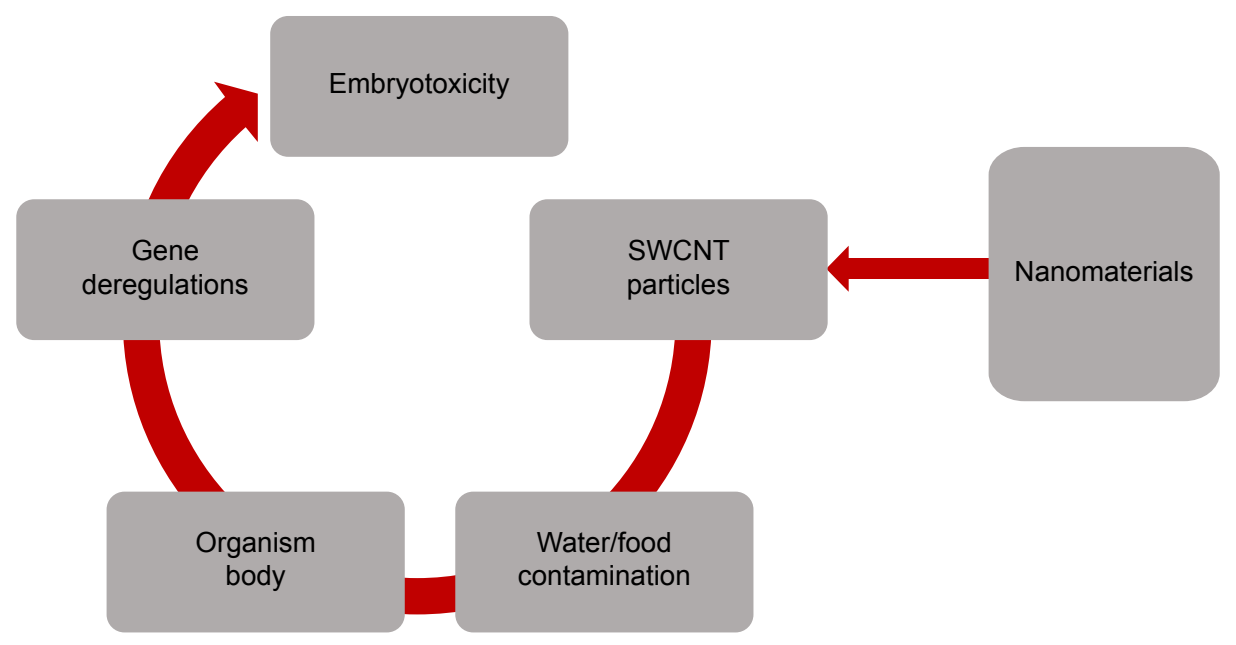

Figure 3 Schematic showing the relationship between SWCNTs and embryotoxicity.

Notes: Water and/or food could be contaminated by SWCNTs; therefore, these particles can penetrate organism and embryonic cells and thereby induce apoptosis and/or cell death via the alteration of their key regulators genes.

Abbreviation: SWCNTs, single-walled carbon nanotubes.

caspase activity in CD45(+) cells. On the other hand, phenotypic expression analysis and functional colony forming units showed significant ex vivo expansion of hematopoietic stem and progenitor cells. The data of this study suggested that f-SWCNT-COOH could improve repopulation of immunodeficient mice models with minimal acute or subacute symptoms of graft-versus-host disease. ${ }^{68}$ Separately, Campagnolo et $\mathrm{al}^{69}$ examined the effect of SWCNTs with polyethylene glycol (PEG) chains for their use as biomedical carriers in mammalian pregnancy. They reported no adverse effects both on embryos and dams up to the dose of $10 \mu \mathrm{g} /$ mouse. However, they revealed occasional teratogenic effects, associated with placental damage at a dose of $30 \mu \mathrm{g} / \mathrm{mouse}$; this dose is equivalent to an $\sim 70 \mathrm{mg}$ dose for a $60 \mathrm{~kg}$ pregnant patient. It is reasonable to assume that such a dose might be used for biomedical application of PEG-modified CNTs in humans. However, the authors of this study stated that PEGSWCNTs might cause occasional teratogenic effects in mice beyond a threshold dose. Therefore, they conclude that the data of this investigation should be considered if exposing women during pregnancy. ${ }^{69}$

Finally, all of the above studies, including ours, suggest that SWCNTs could harm the normal development of the embryo from aquatic to mammalian (Table 1) including human via the deregulation of specific genes related to cell proliferation, apoptosis, survival, cell cycle, and angiogenesis. Meanwhile, it is important to emphasize that organism embryos could be simply exposed to NPs via water and/or food contaminations, which could have a dramatic effect on these organisms and particularly on their embryos (Figure 3).

\section{Conclusion}

In this paper, we aimed to provide a concise review of the most updated understanding of embryotoxicity of SWCNTs. Overall, the limited amount of studies published necessitates more systematic and thorough investigations to elucidate the real effect of SWCNTs and their mechanism in the embryo. Such knowledge will allow the determination of a more rounded safety profile and is mandatory toward harmless use of any kind of nanomaterial, which is not restricted to SWCNTs.

Meanwhile, it seems that common critical parameters that determine SWCNTs toxicity include the chemical nature of surface modifications, surface charge, nanotube structure, and nanotube surface area available for interactions; ${ }^{31,70}$ thus, additional studies are necessary to explore the exact role of these parameters in induced toxicity by CNTs on the organisms and their embryos. Finally, we believe that modification of CNTs structure could have an important influence on limiting their toxic effect on human health, including the normal development of the embryo, which could allow us to use them in the industry as well as in the medical field without any hesitation.

\section{Acknowledgments}

We are thankful to Mrs A Kassab and Ms J Bitharas for their reading of the manuscript. The research works from $\mathrm{Dr} \mathrm{Al}$ Moustafa's laboratory have been supported by the Canadian Institutes for Health Research, the Cancer Research Society Inc. of Canada, the National Colorectal Cancer Campaign, the Fonds de la Recherche en Santé du Québec 
(FRSQ-Réseau du Cancer), and by the College of Medicine at Qatar University.

\section{Disclosure}

These authors report no conflict of interest in this work.

\section{References}

1. Chellaram C, Murugaboopathi G, John A, et al. Significance of nanotechnology in food industry. APCBEE Procedia. 2014;8:109-113.

2. Khot L, Sankaran S, Maja J, Ehsani R, Schuster E. Applications of nanomaterials in agricultural production and crop protection: a review. Crop Prot. 2012;35:64-70.

3. Kuan CY, Yee-Fung W, Yuen KH, Liong MT. Nanotech: propensity in foods and bioactives. Crit Rev Food Sci Nutr. 2012;52(1): $55-71$.

4. Lee J, Mahendra S, Alvarez PJ. Nanomaterials in the construction industry: a review of their applications and environmental health and safety considerations. ACS Nano. 2010;4(7):3580-3590.

5. Lei $\mathrm{Y}, \mathrm{Wu} \mathrm{Q}$, Celemons $\mathrm{C}$, Yao F, Xu Y. Influence of nanoclay on properties of HDPE/wood composites. J Appl Polym Sci. 2007;106: 3958-3966.

6. Manzetti S, Vasilache D, Francesco E. Emerging carbon-based nanosensor devices: structures, functions and applications. Adv Manuf. 2015;3(1):63-72.

7. Sanchez F, Sobolev K. Nanotechnology in concrete - a review. Constr Build Mater. 2010;24(11):2060-2071.

8. Thompson D. Using gold nanoparticles for catalysis. Nanotoday. 2007;2(4):40-43.

9. Monge-Fuentes V, Muehlmann LA, de Azevedo RB. Perspectives on the application of nanotechnology in photodynamic therapy for the treatment of melanoma. Nano Rev. 2014;5.

10. Wang C, Xu L, Liang C, Xiang J, Peng R, Liu Z. Immunological responses triggered by photothermal therapy with carbon nanotubes in combination with anti-CTLA-4 therapy to inhibit cancer metastasis. Adv Mater. 2014;26(48):8154-8162.

11. Zhao X, Liu R. Recent progress and perspectives on the toxicity of carbon nanotubes at organism, organ, cell, and biomacromolecule levels. Environ Int. 2012;40:244-255.

12. Moghimi SM, Hunter AC, Andresen TL. Factors controlling nanoparticle pharmacokinetics: an integrated analysis and perspective. Аnпи Rev Pharmacol Toxicol. 2012;52:481-503.

13. Rees M, Moghimi SM. Nanotechnology: from fundamental concepts to clinical applications for healthy aging. Nanomedicine. 2012;8 Suppl 1: S1-S4.

14. Du P, Zhao J, Mashayekhi H, Xing B. Adsorption of bovine serum albumin and lysozyme on functionalized carbon nanotubes. $J$ Phys Chem. 2014;118(38):22249-22257.

15. Koromilas ND, Lainioti G, Gialeli C, et al. Preparation and toxicological assessment of functionalized carbon nanotube-polymer hybrids. PLoS One. 2014;9(9):e107029.

16. Peynshaert K, Manshian BB, Joris F, et al. Exploiting intrinsic nanoparticle toxicity: the pros and cons of nanoparticle-induced autophagy in biomedical research. Chem Rev. 2014;114(15): 7581-7609.

17. Rivera Gil P, Oberdorster G, Elder A, Puntes V, Parak WJ. Correlating physico-chemical with toxicological properties of nanoparticles: the present and the future. ACS Nano. 2010;4(10):5527-5531.

18. Siu KS, Zheng X, Liu Y, et al. Single-walled carbon nanotubes noncovalently functionalized with lipid modified polyethylenimine for siRNA delivery in vitro and in vivo. Bioconjug Chem. 2014;25(10): 1744-1751.

19. Tang S, Tang Y, Zhong L, et al. Short- and long-term toxicities of multiwalled carbon nanotubes in vivo and in vitro. J Appl Toxicol. 2012; 32(11):900-912.
20. Chen R, Zhang L, Ge C, et al. Subchronic toxicity and cardiovascular responses in spontaneously hypertensive rats after exposure to multiwalled carbon nanotubes by intratracheal instillation. Chem Res Toxicol. 2015;28(3):440-450.

21. Czarny B, Georgin D, Berthon F, et al. Carbon nanotube translocation to distant organs after pulmonary exposure: insights from in situ (14)C-radiolabeling and tissue radioimaging. ACS Nano. 2014;8(6): $5715-5724$.

22. Lacerda L, Bianco A, Prato M, Kostarelos K. Carbon nanotubes as nanomedicines: from toxicology to pharmacology. Adv Drug Deliv Rev. 2006;58(14):1460-1470.

23. Shvedova AA, Kisin ER, Porter D, et al. Mechanisms of pulmonary toxicity and medical applications of carbon nanotubes: two faces of Janus? Pharmacol Ther. 2009;121(2):192-204.

24. Su Y, Yan X, Pu Y, Xiao F, Wang D, Yang M. Risks of single-walled carbon nanotubes acting as contaminants-carriers: potential release of phenanthrene in Japanese medaka (Oryzias latipes). Environ Sci Technol. 2013;47(9):4704-4710.

25. Asharani PV, Serina NG, Nurmawati MH, Wu YL, Gong Z, Valiyaveettil S. Impact of multi-walled carbon nanotubes on aquatic species. J Nanosci Nanotechnol. 2008;8(7):3603-3609.

26. Cheng J, Chan CM, Veca LM, et al. Acute and long-term effects after single loading of functionalized multi-walled carbon nanotubes into zebrafish (Danio rerio). Toxicol Appl Pharmacol. 2009;235(2): 216-225.

27. Cheng J, Flahaut E, Cheng SH. Effect of carbon nanotubes on developing zebrafish (Danio rerio) embryos. Environ Toxicol Chem. 2007;26(4):708-716.

28. Roman D, Yasmeen A, Mireuta M, Stiharu I, Al Moustafa AE. Significant toxic role for single-walled carbon nanotubes during normal embryogenesis. Nanomedicine. 2013;9(7):945-950.

29. Tong L, Zhang W, Hang H, Yu Z, Chu PK, Xu A. Toxicity of carbon nanotubes to $\mathrm{p} 21$ and hus1 gene deficient mammalian cells. J Nanosci Nanotechnol. 2011;11(12):11001-11005.

30. Ong KJ, Zhao X, Thistle ME, et al. Mechanistic insights into the effect of nanoparticles on zebrafish hatch. Nanotoxicology. 2014;8(3): 295-304.

31. Madani SY, Mandel A, Seifalian AM. A concise review of carbon nanotube's toxicology. Nano Rev. 2013;4.

32. Sinha N, Yeow JT. Carbon nanotubes for biomedical applications. IEEE Trans Nanobioscience. 2005;4(2):180-195.

33. Saito R, Fujita M, Dresselhaus M. Electronic structure of chiral graphene tubules. Appl Phys Lett. 1992;60:2204-2206.

34. Sidhu NK, Rastogi AC. Vertically aligned ZnO nanorod core-polypyrrole conducting polymer sheath and nanotube arrays for electrochemical supercapacitor energy storage. Nanoscale Res Lett. 2014;9(1):453.

35. Wei D, Liu Y. The intramolecular junctions of carbon nanotubes. Adv Matt. 2008;20:2815-2841.

36. Mehra NK, Mishra V, Jain NK. A review of ligand tethered surface engineered carbon nanotubes. Biomaterials. 2014;35(4):1267-1283.

37. Tan Y, Guo Q, Xie Q, et al. Single-walled carbon nanotubes (SWCNTs)assisted cell-systematic evolution of ligands by exponential enrichment (cell-SELEX) for improving screening efficiency. Anal Chem. 2014; 86(19):9466-9472.

38. Baughman RH, Zakhidov AA, de Heer WA. Carbon nanotubes - the route toward applications. Science. 2002;297(5582):787-792.

39. Charbgoo F, Behmanesh M, Nikkhah M. Enhanced reduction of singlewall carbon nanotube cytotoxicity in vitro: applying a novel method of arginine functionalization. Biotechnol Appl Biochem. 2015;62(5): 598-605.

40. Ibrahim I, Bachmatiuk A, Warner JH, Buchner B, Cuniberti G, Rummeli MH. CVD-grown horizontally aligned single-walled carbon nanotubes: synthesis routes and growth mechanisms. Small. 2012; 8(13):1973-1992.

41. Bethune D, Kiang C, de Vries M, et al. Cobalt-catalysed growth of carbon nanotubes with single-atomic-layer walls. Nature. 1993:605-607. 
42. Iijima S, Ichihashi T. Single-shell carbon nanotubes of 1-nm diameter. Nature. 1993;363:603-605.

43. Chakravarty P, Marches R, Zimmerman NS, et al. Thermal ablation of tumor cells with antibody-functionalized single-walled carbon nanotubes. Proc Natl Acad Sci U S A. 2008;105(25):8697-8702.

44. Hu L, Gao S, Ding X, et al. Photothermal-responsive single-walled carbon nanotube-based ultrathin membranes for on/off switchable separation of oil-in-water nanoemulsions. ACS Nano. 2015;9(5):4835-4842.

45. Kam NW, O'Connell M, Wisdom JA, Dai H. Carbon nanotubes as multifunctional biological transporters and near-infrared agents for selective cancer cell destruction. Proc Natl Acad Sci USA. 2005;102(33): 11600-11605.

46. Hong G, Diao S, Antaris AL, Dai H. Carbon nanomaterials for biological imaging and nanomedicinal therapy. Chem Rev. 2015;115(19): 10816-10906.

47. Zerda A, Zavaleta C, Keren S, et al. Photoacoustic molecular imaging in living mice utilizing targeted carbon nanotubes. Nature Nanotechnol. 2008;3:557-562.

48. Cherukuri P, Bachilo SM, Litovsky SH, Weisman RB. Near-infrared fluorescence microscopy of single-walled carbon nanotubes in phagocytic cells. J Am Chem Soc. 2004;126(48):15638-15639.

49. Welsher K, Liu Z, Daranciang D, Dai H. Selective probing and imaging of cells with single walled carbon nanotubes as near-infrared fluorescent molecules. Nano Lett. 2008;8(2):586-590.

50. Giraldo JP, Landry MP, Kwak SY, et al. A ratiometric sensor using single chirality near-infrared fluorescent carbon nanotubes: application to in vivo monitoring. Small. 2015;11(32):3973-3984.

51. Alazzam A, Mfoumou E, Stiharu I, et al. Identification of deregulated genes by single wall carbon-nanotubes in human normal bronchial epithelial cells. Nanomedicine. 2010;6(4):563-569.

52. Darne C, Terzetti F, Coulais C, et al. Cytotoxicity and genotoxicity of panel of single- and multiwalled carbon nanotubes: in vitro effects on normal Syrian hamster embryo and immortalized v79 hamster lung cells. J Toxicol. 2014;2014:872195.

53. Hilton GM, Taylor AJ, McClure CD, Parsons GN, Bonner JC, Bereman MS. Toxicoproteomic analysis of pulmonary carbon nanotube exposure using LC-MS/MS. Toxicology. 2015;329:80-87.

54. Scown TM, van Aerle R, Tyler CR. Review: Do engineered nanoparticles pose a significant threat to the aquatic environment? Crit Rev Toxicol. 2010;40(7):653-670.

55. Lam CW, James JT, McCluskey R, Hunter RL. Pulmonary toxicity of single-wall carbon nanotubes in mice 7 and 90 days after intratracheal instillation. Toxicol Sci. 2004;77(1):126-134.

56. Li Z, Hulderman T, Salmen R, et al. Cardiovascular effects of pulmonary exposure to single-wall carbon nanotubes. Environ Health Perspect. 2007;115(3):377-382.

57. Mangum JB, Turpin EA, Antao-Menezes A, Cesta MF, Bermudez E, Bonner JC. Single-walled carbon nanotube (SWCNT)-induced interstitial fibrosis in the lungs of rats is associated with increased levels of PDGF mRNA and the formation of unique intercellular carbon structures that bridge alveolar macrophages in situ. Part Fibre Toxicol. 2006;3:15
58. Mercer RR, Scabilloni J, Wang L, et al. Alteration of deposition pattern and pulmonary response as a result of improved dispersion of aspirated single-walled carbon nanotubes in a mouse model. Am J Physiol Lung Cell Mol Physiol. 2008;294(1):L87-L97.

59. Shvedova AA, Kagan VE. The role of nanotoxicology in realizing the 'helping without harm' paradigm of nanomedicine: lessons from studies of pulmonary effects of single-walled carbon nanotubes. J Intern Med. 2010;267(1):106-118.

60. Shvedova AA, Kisin ER, Mercer R, et al. Unusual inflammatory and fibrogenic pulmonary responses to single-walled carbon nanotubes in mice. Am J Physiol Lung Cell Mol Physiol. 2005;289(5):L698-L708.

61. Warheit DB, Laurence BR, Reed KL, Roach DH, Reynolds GA, Webb TR. Comparative pulmonary toxicity assessment of single-wall carbon nanotubes in rats. Toxicol Sci. 2004;77(1):117-125.

62. Leeuw TK, Reith RM, Simonette RA, et al. Single-walled carbon nanotubes in the intact organism: near-IR imaging and biocompatibility studies in Drosophila. Nano Lett. 2007;7(9):2650-2654.

63. Philbrook NA, Walker VK, Afrooz AR, Saleh NB, Winn LM. Investigating the effects of functionalized carbon nanotubes on reproduction and development in Drosophila melanogaster and CD-1 mice. Reprod Toxicol. 2011;32(4):442-448.

64. Belyanskaya L, Weigel S, Hirsch C, Tobler U, Krug HF, Wick P. Effects of carbon nanotubes on primary neurons and glial cells. Neurotoxicology. 2009;30(4):702-711.

65. Pietroiusti A, Massimiani M, Fenoglio I, et al. Low doses of pristine and oxidized single-wall carbon nanotubes affect mammalian embryonic development. ACS Nano. 2011;5(6):4624-4633.

66. Yang H, Liu C, Yang D, Zhang H, Xi Z. Comparative study of cytotoxicity, oxidative stress and genotoxicity induced by four typical nanomaterials: the role of particle size, shape and composition. $J$ Appl Toxicol. 2009;29(1):69-78.

67. Bobrinetskii II, Morozov RA, Seleznev AS, Podchernyaeva RY, Lopatina OA. Proliferative activity and viability of fibroblast and glioblastoma cell on various types of carbon nanotubes. Bull Exp Biol Med. 2012;153(2):259-262.

68. Bari S, Chu PP, Lim A, et al. Protective role of functionalized single walled carbon nanotubes enhance ex vivo expansion of hematopoietic stem and progenitor cells in human umbilical cord blood. Nanomedicine 2013;9(8):1304-1316.

69. Campagnolo L, Massimiani M, Palmieri G, et al. Biodistribution and toxicity of pegylated single wall carbon nanotubes in pregnant mice. Part Fibre Toxicol. 2013;10:21.

70. Shvedova AA, Pietroiusti A, Fadeel B, Kagan VE. Mechanisms of carbon nanotube-induced toxicity: focus on oxidative stress. Toxicol Appl Pharmacol. 2012;261(2):121-133.
International Journal of Nanomedicine

\section{Publish your work in this journal}

The International Journal of Nanomedicine is an international, peerreviewed journal focusing on the application of nanotechnology in diagnostics, therapeutics, and drug delivery systems throughout the biomedical field. This journal is indexed on PubMed Central, MedLine, CAS, SciSearch ${ }^{\circledR}$, Current Contents ${ }^{\circledR} /$ Clinical Medicine,

\section{Dovepress}

Journal Citation Reports/Science Edition, EMBase, Scopus and the Elsevier Bibliographic databases. The manuscript management system is completely online and includes a very quick and fair peer-review system, which is all easy to use. Visit http://www.dovepress.com/ testimonials.php to read real quotes from published authors. 